\title{
An Empirical Analysis of Unpaid Leave in Taiwan
}

\author{
Shu-Hsi Ho ${ }^{1}$ and Wen-Shai Hung ${ }^{2}$ \\ ${ }^{1}$ Department of International Business, Ling Tung University, 1 Ling Tung Road, Taichung 408, Taiwan \\ ${ }^{2}$ Department of Business Administration, Providence University, Taichung, Taiwan
}

Correspondence should be addressed to Shu-Hsi Ho; susie@teamail.ltu.edu.tw

Received 23 August 2014; Revised 19 October 2014; Accepted 19 October 2014; Published 12 November 2014

Academic Editor: Thanasis Stengos

Copyright (C) 2014 S.-H. Ho and W.-S. Hung. This is an open access article distributed under the Creative Commons Attribution License, which permits unrestricted use, distribution, and reproduction in any medium, provided the original work is properly cited.

\begin{abstract}
This paper investigates the factors influencing unpaid leave or furlough in Taiwan. The data used is from the First Social Image Survey in 2009, which focused on work situation, cross-strait relations, interpersonal trust, institutional trust, and other related issues. The sample ages are from 19 to 89 . The method used is probit modelling for examining the influences on unpaid leave. The main empirical results find that older workers, people with highest educational attainment, widows and widowers, middle class workers, and workers living in eastern areas are less likely to take unpaid leave from the labour market. In particular, male Mainlander workers are more likely to take unpaid leave. Moreover, female workers with highest educational attainment, widowed, and of middle class are less likely to take unpaid leave. Finally, workers with high earnings are less likely to take unpaid leave, but female workers with high family income and female workers who are divorced or separated have a higher probability of unpaid leave.
\end{abstract}

\section{Introduction}

Due to the 2008 global financial crisis, many Taiwanese business enterprises faced difficult situations, such as the decreasing orders, reduced salaries, and working stoppages, forcing many companies to shut down production to adjust capacity while employees faced reduction in working hours, forced vacations, benefits, pay, or even layoffs. In order to avoid mass layoffs, resulting in job losses or serious social problems, in 2008 the government tried to persuade manufacturers to use unpaid leave.

The use of unpaid leave or furloughs did not originate in Taiwan. For example, the parental and family leave law in Vermont, USA, in 1993, protects employees who need to take time off from work. The law requires some Vermont employers to provide unpaid time off from work to some employees. There are three types of leave, including the following: (1) parental leave: female employees can take parental leave during their own pregnancies; male and female employees can take leave for their new born or newly adopted child; (2) family leave: employees can take family leave if they are seriously ill or if certain family members are seriously ill; (3) short-term family leave: employees can take short-term family leave for activities that directly relate to their child's academic advancement; employees can take short-term family leave to respond to a medical emergency of their child, step-child, foster-child, ward, spouse, civil union partner, parent, or parent-in-law, to go to medical appointments with a child, step-child, foster-child, ward, spouse, civil union partner, parent, or parent-in-law, or to go to their own medical appointments. Employees can also take short-term family leave to accompany a parent, parent-in-law, spouse, or civil union partner to other professional appointments that are related to the care or well-being of their family member (please see http://women.vermont.gov/sites/women/files/pdf/Parental_ Family_Leave_Guide.pdf). Moreover, regarding family leave in Canada, female employees are entitled to a standard 17-week unpaid, job-protected maternity leave. In addition, both male and female employees are granted up to 37week unpaid, job-protected parental leave (35 weeks for women if being combined with maternity leave for a total of 52 weeks) in order to care for a new born or newly adopted child (Department of Justice, Canada, "Canada Labour Code (R.S., 1985, c. L-2), Part III: Standard hours, wages, vacations, and holidays." (p. 175). Please see 
http://www.catalyst.org/knowledge/family-leave-us-canadaand-global).

In addition, after the crisis of the bubble economy businesses in Japan, similar practices of unpaid leave or furloughs were also introduced during the 1990s [1]. On the one hand, businesses can avoid firing workers directly; on the other hand, they can reduce costs. Unpaid or administrative leave allows businesses to adopt "shorter working hours to reduce wages" in order to maintain the conditions of labour contracts. The shortening of working hours reduces wage costs while maintaining employment. However, is this response to a short-term and special economic crisis or a long term situation? If it was the latter, employees might become quasiunemployed or subject to frictional unemployment, resulting in job losses and serious social problems. The winner of the 2010 Nobel Prize for Economics, Professor Christopher A. Pissarides, publicly praised the unpaid leave system in Taiwan suggesting that it may provide a double win for employee and enterprise (please see http://podcast.asia.edu.tw/podcast/show_episode/1599).

Most previous empirical studies of employment focused on human capital, such as the impacts of years or levels of employment, professionals, and ranking of schooling in Taiwan. For example, Lin [2] and Chuang [3] analysed the issues surrounding unemployment, job search, and the determinants of wages. Furthermore, Chen [4] discussed the issue of young people not in employment, education, or training (NEETs) using quality analysis and Hung [5] investigated the influencing factors of health and labour force participation among young people in Taiwan. However, few empirical studies have considered the problems of unpaid leave or furlough in Taiwan $[1,6]$. This paper tries to fill this gap and investigates the factors influencing unpaid leave or furlough in Taiwan.

The paper is organized as follows. Section 2 presents some basic facts of labour force participation and unemployment. Section 3 describes the data source. Section 4 presents the model and estimation. Section 5 discusses the empirical results. Section 6 concludes the paper.

\section{Basic Facts of Labour Force Participation and Possible Factors Affecting Unpaid Leave in Taiwan}

According to the report of the Directorate General of Budget, Accounting, and Statistics (DGBAS), the highest labour force participation (LFP) rates by people aged 30-39 gradually increased from $76.1 \%$ in 1990 to $85.3 \%$ in 2013. For those aged $40-49$, the rate also gradually increased from $74.3 \%$ to $81.8 \%$; for those aged 50-59, it remained constant at $60.7 \%$, for the fourth group aged $15-29$ the rate decreased from $55.6 \%$ to $51.1 \%$ and for the final group aged 60 and over it decreased from $25.3 \%$ to $20.9 \%$ during the same period, as shown in Figure 1. The possible reason for the LFP of youngest group gradually decreased that those who might be continuous to study for higher educational attainment. In particular, the numbers of universities and colleges have gone up from 105 in 1986 to 168 in 2013 in Taiwan.

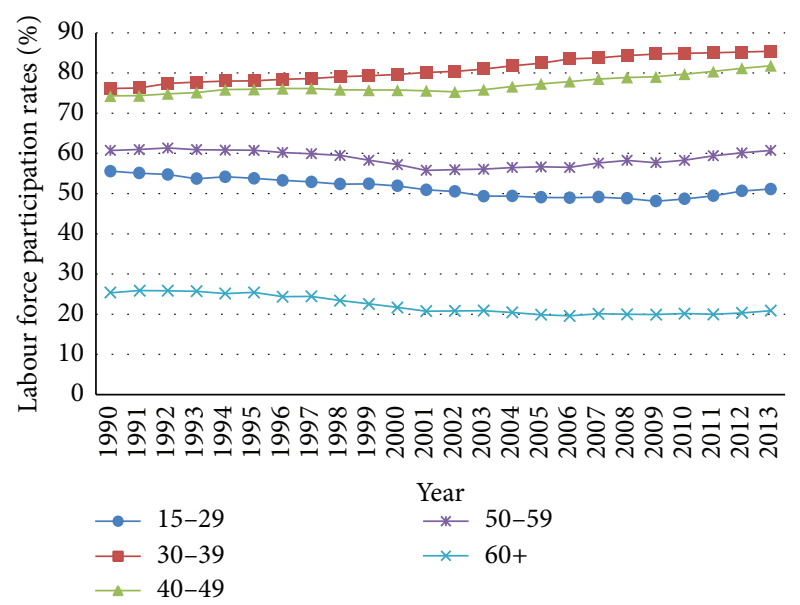

FIGURE 1: Labour force participation rates by different age groups in Taiwan, 1990-2013.

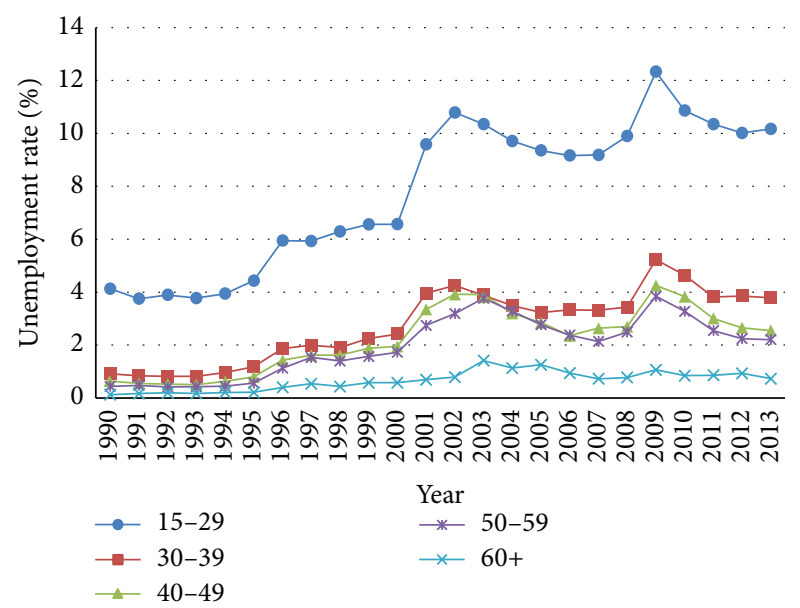

FIGURE 2: Unemployment rates by different age groups in Taiwan, 1990-2013.

However, the highest unemployment rates also belonged to the youngest group, those aged 15-29 gradually rose from $4.1 \%$ in 1990 to $10.2 \%$ in 2013 . This trend became more serious, rising from $6.6 \%$ in 2000 to $10.9 \%$ in 2010 . The unemployment rates of medium aged groups, including those aged 30-39, $40-49$, and 50-59 had been controlled, remaining below $4 \%$ during the same period, as shown in Figure 2. There was a large gap in unemployment rates between the youngest and medium aged groups. This may indicate that the young people have difficulty finding a job and are prone to frictional unemployment and face the problems of unpaid leave or furlough. Moreover, the Taiwanese society faced the problems with negative population growth and declining fertility. The possible reasons depend on the young people with low earnings. It may be difficult for them to buy a house, to marry, and to raise their children. Therefore, the fertility rates of Taiwan become the lowest in the world over the past decade. Adam Smith talked about the issues of wages of labour in $A n$ Inquiry into the Nature and Causes of the Wealth of Nations; he presented the following: "Labour is there so well rewarded, 
that a numerous family of children, instead of being a burden, is a source of opulence and prosperity to the parents" (please see http://www2.hn.psu.edu/faculty/jmanis/adamsmith/wealth-nations.pdf, p. 63).

Therefore, the problems of unpaid leave or furlough may let Taiwan today population become worse and the government needs to consider how to solve these root causes of the crisis. How do variables such as gender, race, economic status, and educational level affect unpaid leave? This paper uses data from the 2009 First Social Image Survey to address this question. Hopefully, it can provide useful suggestions to the government for solving the problems of unpaid leave in Taiwan.

\section{Data}

3.1. Data Source. The data set used in this paper is from the First Social Image Survey (FSIS), 2009 [7], which was conducted by Professor Yang et al. The survey topics included work situation, cross-strait relations, interpersonal trust, institutional trust, and other related issues. This paper is only focused on the work situation, whether family members suffered wage reductions, unpaid leave, unemployment or layoffs, understanding the situations, and further inquiries in such cases, such as whether the rest of the family provided material and psychological assistance.

The sample ages are from 19 to 89 . The total sample has 1256 observations, including 801 people working, 119 unemployed, 26 students, 188 housewives, 119 retired, and 3 others. Therefore, the effective sample of labour force participants has 855 observations from people working and unemployed, who have completely answered all the questions.

3.2. Variables Specification. Probit analysis examines the influences of individual cases of unpaid leave, whether they take or do not take furlough. Hence, the dependent variable is simply specified as $y=1$ if the respondents or their family take unpaid leave and zero otherwise. The explanatory variables include (1) individual characteristic variables: age, gender, race, education, marital status, and health status, (2) social network variables: work positions in social class, family support, and residence, and (3) economic variables: earnings and family income. A full definition of the variables and summary statistics of the sample are given in Table 1.

\section{Empirical Specification}

This section seeks appropriate ways to measure the impact of unpaid leave in Taiwan. This paper uses probit modelling to examine the influences on the use of unpaid leave.

Let $y$ represent the choice of no-pay leave ( $y=1$ if unpaid leave taken, 0 otherwise) and let the two outcomes, furlough and not furlough, be described by the state-specific utilities $U_{y}^{*}[8,9]$ :

$$
U_{y=1}^{*}=x^{\prime} \beta_{1}+u_{1}, \quad U_{y=0}^{*}=x^{\prime} \beta_{0}+u_{0},
$$

where $x^{\prime}$ represents a common set of control variables, $\beta_{0}$ and $\beta_{1}$ are vectors of unknown parameters, and $u_{0}$ and $u_{1}$ represent unobservable (state-specific) taste components. Under this characterisation, an individual will choose to participate if the utility to be got when furloughing (denoted by $U_{y=1}^{*}$ ) exceeds the utility to be had when not furloughing (denoted by $U_{y=0}^{*}$ ). An employee will decide to work if $U_{y=1}^{*}>$ $U_{y=0}^{*}$, and therefore the decision to work is as follows: $y=$ $1\left(U_{y=1}^{*}-U_{y=0}^{*}>0\right)$.

Consequently, the observation rule (1) can be rewritten as

$$
\begin{array}{rlr}
y & =1 \quad\left(U_{y=1}^{*}>U_{y=0}^{*}\right) \\
& =1 \quad\left(x^{\prime} \beta_{1}+u_{1}>x^{\prime} \beta_{0}+u_{0}\right) \\
& =1 \quad\left[\left(u_{1}-u_{0}\right)>-x^{\prime}\left(\beta_{1}-\beta_{0}\right)\right] .
\end{array}
$$

Clearly, both sets of parameters $\beta_{0}$ and $\beta_{1}$ cannot be identified. However, the difference $\beta_{1}-\beta_{0}$ can be identified and can implicitly parameterise the choice model as

$$
y=1 \quad\left(y^{*}>0\right)
$$

where $y^{*}=x^{\prime}\left(\beta_{1}-\beta_{0}\right)+\left(u_{1}-u_{0}\right)=x^{\prime} \beta+u$. Maximum likelihood estimation (hereafter, MLE) considers the probability of observing a sample of behavioural outcomes and characteristics. Consider a sample of $n$ observations $\left\{y_{i}, x_{i}\right\}$ drawn at random from a population, where $y_{i}$ is binary. Assuming the observability criterion $y_{i}=1\left(y_{i}^{*}>0\right)$ for a latent variable equation of the form $y_{i}^{*}=x_{i}^{\prime} \beta+u_{i}$ and assuming that the distribution of $u_{i}$ is standard normal and independent across observations, MLE solves for the parameter vector $\beta$ which is most likely to have generated the data $\left\{y_{i}, x_{i}\right\}$. For any vector $\beta$, the probability of observing the outcome $y_{i}$ conditional on the data $x_{i}$ is

$$
L\left(\beta x_{i}\right)=\prod_{i=1}^{n} \operatorname{Pr}\left(y_{i}=0 \mid x_{i} ; \beta\right)^{1-y_{i}} \cdot \operatorname{Pr}\left(y_{i}=1 \mid x_{i} ; \beta\right)^{y_{i}}
$$

Taking a natural $\log$ to obtain

$$
\begin{aligned}
& \ln L\left(\beta \mid x_{i}\right) \\
& =\sum_{i=1}^{n}\left[\left(1-y_{i}\right) \cdot \ln \operatorname{Pr}\left(y_{i}=0 \mid x_{i} ; \beta\right)+y_{i} \cdot \operatorname{Pr}\left(y_{i}=1 \mid x_{i} ; \beta\right)\right]
\end{aligned}
$$

for the probit model, the following conditions for probability hold:

$$
\begin{gathered}
\operatorname{Pr}\left(y_{i}=1 \mid x_{i} ; \beta\right)=\Phi\left(x_{i}^{\prime} \beta\right), \\
\operatorname{Pr}\left(y_{i}=0 \mid x_{i} ; \beta\right)=1-\Phi\left(x_{i}^{\prime} \beta\right),
\end{gathered}
$$

where $\Phi(x)$ is the standard normal cumulative distribution function. Substituting the above into (5) gives a conditional likelihood function of the form:

$$
\begin{aligned}
\ln L & \left(\beta \mid x_{i}\right) \\
& =\sum_{i=1}^{n}\left\{\left(1-y_{i}\right) \cdot \ln \left[1-\Phi\left(x_{i}^{\prime} \beta\right)\right]+y_{i} \cdot \ln \Phi\left(x_{i}^{\prime} \beta\right)\right\} .
\end{aligned}
$$


TABLE 1: Descriptive statistics of variables.

\begin{tabular}{|c|c|c|c|}
\hline Variables & Description & Mean & Standard error \\
\hline Furlough & $\begin{array}{l}1=\text { no-pay leave cases by interviewers or their family, } \\
0=\text { otherwise }\end{array}$ & 0.304 & $(0.460)$ \\
\hline Agel & $\begin{array}{l}1=\text { aged from } 18 \text { to } 29 \\
0=\text { otherwise }\end{array}$ & 0.129 & $(0.336)$ \\
\hline Age2 & $\begin{array}{l}1=\text { aged from } 30 \text { to } 39 \\
0=\text { otherwise }\end{array}$ & 0.284 & $(0.451)$ \\
\hline Age3 & $\begin{array}{l}1=\text { aged from } 40 \text { to } 49 \\
0=\text { otherwise }\end{array}$ & 0.305 & $(0.461)$ \\
\hline Age4 & $\begin{array}{l}1=\text { aged from } 50 \text { to } 59 \\
0=\text { otherwise }\end{array}$ & 0.199 & $(0.399)$ \\
\hline Age5 & $\begin{array}{l}1=\text { aged } 60 \text { and over, } \\
0=\text { otherwise }\end{array}$ & 0.082 & $(0.274)$ \\
\hline Gender & $1=$ men, $0=$ women & 0.567 & $(0.495)$ \\
\hline Racel & $1=$ Fujianese, $0=$ otherwise & 0.749 & $(0.433)$ \\
\hline Race2 & $1=$ Hakka, $0=$ otherwise & 0.111 & $(0.314)$ \\
\hline Race3 & $\begin{array}{l}1=\text { Mainlander } \\
0=\text { otherwise }\end{array}$ & 0.128 & $(0.335)$ \\
\hline Race4 & $\begin{array}{l}1=\text { aboriginal, } \\
0=\text { otherwise }\end{array}$ & 0.011 & $(0.102)$ \\
\hline Edul & $1=$ informal and $1-6$ years of schooling, $0=$ otherwise & 0.078 & $(0.269)$ \\
\hline Edu2 & $\begin{array}{l}1=7-12 \text { years of schooling } \\
0=\text { otherwise }\end{array}$ & 0.409 & $(0.492)$ \\
\hline Edu3 & $\begin{array}{l}1=13-16 \text { years of schooling, } \\
0=\text { otherwise }\end{array}$ & 0.436 & $(0.496)$ \\
\hline Edu4 & $\begin{array}{l}1=17 \text { years and over of schooling, } \\
0=\text { otherwise }\end{array}$ & 0.076 & $(0.265)$ \\
\hline Maritall & $1=$ single, $0=$ otherwise & 0.223 & $(0.416)$ \\
\hline Marital2 & $1=$ married, $0=$ otherwise & 0.696 & $(0.460)$ \\
\hline Marital3 & $\begin{array}{l}1=\text { divorced and separated } \\
0=\text { otherwise }\end{array}$ & 0.058 & $(0.235)$ \\
\hline Marital4 & $\begin{array}{l}1=\text { spouse deceased } \\
0=\text { otherwise }\end{array}$ & 0.022 & $(0.147)$ \\
\hline Position1 & $\begin{array}{l}1=\text { low level in social class, } \\
0=\text { otherwise }\end{array}$ & 0.139 & $(0.346)$ \\
\hline Position2 & $\begin{array}{l}1=\text { medium less level, } \\
0=\text { otherwise }\end{array}$ & 0.228 & $(0.419)$ \\
\hline Position3 & $\begin{array}{l}1=\text { medium level, } \\
0=\text { otherwise }\end{array}$ & 0.391 & $(0.488)$ \\
\hline Position 4 & $\begin{array}{l}1=\text { medium more level, } \\
0=\text { otherwise }\end{array}$ & 0.110 & $(0.313)$ \\
\hline Position5 & $\begin{array}{l}1=\text { worker level, } \\
0=\text { otherwise }\end{array}$ & 0.129 & $(0.336)$ \\
\hline Position6 & $\begin{array}{l}1=\text { high level, } \\
0=\text { otherwise }\end{array}$ & 0.002 & $(0.048)$ \\
\hline Happy & $\begin{array}{l}1=\text { have } \text { a good feeling } \\
0=\text { otherwise }\end{array}$ & 0.668 & $(0.471)$ \\
\hline Health & $\begin{array}{l}1=\text { poor health, } \\
0=\text { otherwise }\end{array}$ & 0.063 & $(0.243)$ \\
\hline Residencel & $\begin{array}{l}1=\text { live in north areas, } \\
0=\text { otherwise }\end{array}$ & 0.459 & $(0.498)$ \\
\hline
\end{tabular}


TABLE 1: Continued.

\begin{tabular}{llll}
\hline Variables & Description & Mean & Standard error \\
\hline Residence2 & $1=$ live in centre areas, & 0.215 & \\
& $0=$ otherwise & & $(0.411)$ \\
Residence3 & $=$ live in south areas, & 0.279 \\
& $0=$ otherwise & & $(0.449)$ \\
Residence4 & $=$ live in east areas, & 0.045 & $(0.208)$ \\
Earnings & $0=$ otherwise & 10.472 & $(0.446)$ \\
Income & Earnings $=\log ($ earningshat $)$ & 11.168 & $(0.359)$ \\
\hline
\end{tabular}

Notes.

(1) According to the survey of First Social Image Survey in 2009, total sample has 1256 observations, including 801 people working, 119 unemployed, 26 students, 188 housewives, 119 retired, and 3 others. Therefore, the effective sample of labour force only has 855 observations from people working and unemployed, who have completely answered all the questions.

(2) The variables of Earnings and Income are predicted by the relative variables and measured in log form.

TABLE 2: Probit coefficient estimates of unpaid leave without economic factor.

\begin{tabular}{|c|c|c|c|c|c|c|}
\hline \multirow{2}{*}{$\begin{array}{l}\text { Sample } \\
\text { Variables }\end{array}$} & \multicolumn{2}{|c|}{ Overall } & \multicolumn{2}{|c|}{ Male } & \multicolumn{2}{|c|}{ Female } \\
\hline & Coef. & Std. Err. & Coef. & Std. Err. & Coef. & Std. Err. \\
\hline Age2 & -0.078 & $(0.171)$ & -0.130 & $(0.234)$ & 0.026 & $(0.264)$ \\
\hline Age3 & $-0.457^{* *}$ & $(0.189)$ & $-0.624^{* *}$ & $(0.264)$ & -0.295 & $(0.285)$ \\
\hline Age4 & $-0.602^{* * *}$ & $(0.202)$ & $-0.796^{* * *}$ & $(0.277)$ & -0.375 & $(0.316)$ \\
\hline Age5 & $-0.696^{* * *}$ & $(0.265)$ & $-0.996^{* * *}$ & $(0.348)$ & -0.309 & $(0.474)$ \\
\hline Gender & 0.023 & $(0.099)$ & \multicolumn{2}{|c|}{-} & \multicolumn{2}{|c|}{-} \\
\hline Edu2 & 0.192 & $(0.210)$ & 0.128 & $(0.277)$ & 0.182 & $(0.342)$ \\
\hline Edu3 & -0.031 & $(0.228)$ & 0.052 & $(0.295)$ & -0.301 & $(0.379)$ \\
\hline Edu4 & $-0.511^{*}$ & $(0.301)$ & -0.349 & $(0.396)$ & $-0.963^{*}$ & $(0.498)$ \\
\hline Marit2 & 0.048 & $(0.142)$ & 0.234 & $(0.195)$ & -0.278 & $(0.226)$ \\
\hline Marit3 & -0.269 & $(0.241)$ & -0.623 & $(0.365)$ & -0.107 & $(0.346)$ \\
\hline Marit4 & $-0.741^{*}$ & $(0.442)$ & 0.077 & $(0.735)$ & $-1.521^{* *}$ & $(0.619)$ \\
\hline Race2 & 0.032 & $(0.153)$ & -0.037 & $(0.201)$ & 0.163 & $(0.250)$ \\
\hline Race3 & $0.315^{* *}$ & $(0.146)$ & $0.328^{*}$ & $(0.197)$ & 0.318 & $(0.231)$ \\
\hline Race4 & 0.261 & $(0.463)$ & 0.317 & $(0.624)$ & 0.208 & $(0.785)$ \\
\hline Position2 & -0.209 & $(0.161)$ & -0.265 & $(0.208)$ & -0.253 & $(0.267)$ \\
\hline Position3 & $-0.559^{* * *}$ & $(0.157)$ & $-0.525^{* *}$ & $(0.209)$ & $-0.688^{* * *}$ & $(0.253)$ \\
\hline Position4 & -0.252 & $(0.205)$ & -0.142 & $(0.274)$ & -0.346 & $(0.325)$ \\
\hline Position5 & 0.041 & $(0.177)$ & 0.221 & $(0.223)$ & -0.291 & $(0.308)$ \\
\hline Position6 & 0.426 & $(0.890)$ & 0.334 & $(0.918)$ & & \\
\hline Happy & -0.152 & $(0.103)$ & $-0.316^{* *}$ & $(0.136)$ & 0.021 & $(0.170)$ \\
\hline Health & 0.158 & $(0.197)$ & 0.338 & $(0.334)$ & -0.041 & $(0.267)$ \\
\hline Residence2 & 0.100 & $(0.123)$ & 0.190 & $(0.173)$ & 0.057 & $(0.184)$ \\
\hline Residence3 & -0.082 & $(0.115)$ & -0.175 & $(0.155)$ & 0.088 & $(0.186)$ \\
\hline Residence4 & $-0.851^{* * *}$ & $(0.284)$ & $-0.983^{* * *}$ & $(0.376)$ & -0.599 & $(0.478)$ \\
\hline Constant & 0.108 & $(0.276)$ & 0.194 & $(0.343)$ & 0.298 & $(0.453)$ \\
\hline $\bar{N}$ & \multicolumn{2}{|c|}{855} & \multicolumn{2}{|c|}{485} & \multicolumn{2}{|c|}{370} \\
\hline Log likelihood & \multicolumn{2}{|c|}{-483.384} & \multicolumn{2}{|c|}{-271.275} & \multicolumn{2}{|c|}{-201.390} \\
\hline LR chi2 (24) & \multicolumn{2}{|c|}{$83.67^{* * *}$} & \multicolumn{2}{|c|}{$62.15^{* * *}$} & \multicolumn{2}{|c|}{$42.27^{* * *}$} \\
\hline
\end{tabular}

Notes.

(1) The effective samples have 855 observations, including 485 males and 370 females.

(2) The omitted (reference) categories are as follows: Agel for age groups dummy variable; female for gender; Edul for educational groups; Maritl for marital status; Racel for race groups; Positionl for social class groups; and Residencel for residence areas.

(3) ${ }^{*}$ Effect is significant at $P \leq 0.10 ;{ }^{* *} P \leq 0.05$; and ${ }^{* * *} P \leq 0.01$.

(4) Goodness of fit is as follows: the result of Log-likelihood ratio test can reject the hypothesis that all coefficients except for the intercept are 0 at the 0.01 level. Considering the Gender variable, the LR chi2 of males and females are LR chi2 (23), respectively. 
TABLE 3: Probit marginal effect estimates of unpaid leave without economic factor.

\begin{tabular}{|c|c|c|c|c|c|c|}
\hline \multirow{2}{*}{$\begin{array}{l}\text { Sample } \\
\text { Variables } \\
\end{array}$} & \multicolumn{2}{|c|}{ Overall } & \multicolumn{2}{|c|}{ Male } & \multicolumn{2}{|c|}{ Female } \\
\hline & $d y / d x$ & Std. Err. & $d y / d x$ & Std. Err. & $d y / d x$ & Std. Err. \\
\hline Age2 & -0.026 & $(0.058)$ & -0.044 & $(0.081)$ & 0.008 & $(0.086)$ \\
\hline Age3 & $-0.155^{* *}$ & $(0.064)$ & $-0.215^{* *}$ & $(0.091)$ & -0.096 & $(0.093)$ \\
\hline Age4 & $-0.205^{* * *}$ & $(0.069)$ & $-0.274^{* * *}$ & $(0.095)$ & -0.122 & $(0.103)$ \\
\hline Age5 & $-0.237^{* * *}$ & $(0.090)$ & $-0.343^{* * *}$ & $(0.119)$ & -0.101 & $(0.155)$ \\
\hline Gender & 0.007 & $(0.033)$ & \multicolumn{2}{|c|}{-} & \multicolumn{2}{|c|}{-} \\
\hline Edu2 & 0.065 & $(0.071)$ & 0.044 & $(0.095)$ & 0.059 & $(0.112)$ \\
\hline Edu3 & -0.011 & $(0.077)$ & 0.018 & $(0.101)$ & -0.098 & $(0.124)$ \\
\hline Edu4 & $-0.174^{*}$ & $(0.102)$ & -0.120 & $(0.136)$ & $-0.315^{*}$ & $(0.162)$ \\
\hline Marit2 & 0.016 & $(0.048)$ & 0.081 & $(0.067)$ & -0.091 & $(0.073)$ \\
\hline Marit3 & -0.091 & $(0.082)$ & $-0.214^{*}$ & $(0.125)$ & -0.035 & $(0.113)$ \\
\hline Marit4 & $-0.252^{*}$ & $(0.150)$ & 0.026 & $(0.253)$ & $-0.497^{* *}$ & $(0.199)$ \\
\hline Race2 & 0.011 & $(0.052)$ & -0.012 & $(0.069)$ & 0.053 & $(0.081)$ \\
\hline Race3 & $0.107^{* *}$ & $(0.049)$ & $0.113^{*}$ & $(0.068)$ & 0.104 & $(0.075)$ \\
\hline Race4 & 0.088 & $(0.157)$ & 0.109 & $(0.214)$ & 0.068 & $(0.256)$ \\
\hline Position2 & -0.071 & $(0.054)$ & -0.091 & $(0.071)$ & -0.083 & $(0.087)$ \\
\hline Position3 & $-0.191^{* * *}$ & $(0.053)$ & $-0.181^{* *}$ & $(0.071)$ & $-0.225^{* * *}$ & $(0.082)$ \\
\hline Position4 & -0.085 & $(0.070)$ & -0.048 & $(0.094)$ & -0.113 & $(0.106)$ \\
\hline Position5 & 0.014 & $(0.060)$ & 0.076 & $(0.076)$ & -0.095 & $(0.101)$ \\
\hline Position6 & 0.145 & $(0.303)$ & 0.115 & $(0.316)$ & & \\
\hline Happy & -0.051 & $(0.035)$ & $-0.108^{* *}$ & $(0.046)$ & 0.007 & $(0.055)$ \\
\hline Health & 0.054 & $(0.067)$ & 0.116 & $(0.115)$ & -0.013 & $(0.087)$ \\
\hline Residence2 & 0.034 & $(0.042)$ & 0.065 & $(0.059)$ & 0.018 & $(0.060)$ \\
\hline Residence3 & -0.028 & $(0.039)$ & -0.060 & $(0.053)$ & 0.029 & $(0.061)$ \\
\hline Residence 4 & $-0.289^{* * *}$ & $(0.096)$ & $-0.338^{* * *}$ & $(0.128)$ & -0.196 & $(0.155)$ \\
\hline Predicted probability & \multicolumn{2}{|c|}{0.286} & \multicolumn{2}{|c|}{0.294} & \multicolumn{2}{|c|}{0.264} \\
\hline Observations & \multicolumn{2}{|c|}{855} & \multicolumn{2}{|c|}{485} & \multicolumn{2}{|c|}{370} \\
\hline
\end{tabular}

Notes.

(1) The $d y / d x$ is for discrete change of dummy from 0 to 1.

(2) Other notes are the same as in Table 2.

The first-order condition requires that

$$
\begin{aligned}
& \frac{\partial \ln L\left(\beta \mid x_{i}\right)}{\partial \beta} \\
& \quad=\sum_{i=1}^{n} \frac{\left[y_{i}-\Phi\left(x_{i}^{\prime} \beta\right)\right]}{\Phi\left(x_{i}^{\prime} \beta\right) \cdot\left[1-\Phi\left(x_{i}^{\prime} \beta\right)\right]} \cdot \phi\left(x_{i}^{\prime} \beta\right) \cdot x_{i}=0,
\end{aligned}
$$

yielding the ML estimate $\widetilde{\beta}$.

\section{Empirical Results}

Table 2 shows the coefficient estimates of unpaid leave without economic factors by probit model. First, for the benchmark individual, all explanatory variables take a value of zero. The benchmark individual in all cases is a single Fujianese woman, aged less than 29, who has primary school or lower education and lives in the north. This benchmark value is reflected in the constant variable in Table 2 , where the probability is

$$
\operatorname{Pr}\left(y_{i}=1 \mid x_{i} ; \beta\right)=\Phi(0.108)=0.543 \text {. }
$$

The effects on the probability of unpaid leave without economic factors can be calculated out for different demographic circumstances [10]. Holding other factors equal, how does the probability change for Mainland workers (Race3)? This situation models changes in the probability of unpaid leave excluding economic factors for Mainland workers:

$$
\operatorname{Pr}\left(y_{i}=1 \mid x_{i} ; \beta\right)=\Phi(0.108+0.315)=0.664 \text {. }
$$

That is, Mainland workers will have a higher probability of unpaid leave without economic factors. Therefore, if the estimated coefficients are positive, the probabilities of work increase. If the estimated coefficients are negative, then the probabilities of work decrease.

Next, the estimated coefficients of Age3, Age4, Age5, Edu4, Marit4, Position3, and Residence4 variables are statistically significantly negative for unpaid leave as shown in Table 2. This means that older workers, people with highest educational attainment, widows and widowers, workers of medium level of social class, and workers living in eastern areas are less likely to take unpaid leave.

For gender factors, Table 2 shows that the estimated coefficients of Age3, Age4, Age5, Position3, Happy, 
TABLE 4: Probit coefficient estimates of unpaid leave with economic factor.

\begin{tabular}{|c|c|c|c|c|c|c|}
\hline \multirow{2}{*}{$\begin{array}{l}\text { Sample } \\
\text { Variables }\end{array}$} & \multicolumn{2}{|c|}{ Overall } & \multicolumn{2}{|c|}{ Male } & \multicolumn{2}{|c|}{ Female } \\
\hline & Coef. & Std. Err. & Coef. & Std. Err. & Coef. & Std. Err. \\
\hline Age2 & 0.314 & $(0.254)$ & 0.382 & $(0.429)$ & 0.451 & $(0.416)$ \\
\hline Age3 & 0.076 & $(0.318)$ & 0.082 & $(0.559)$ & 0.256 & $(0.523)$ \\
\hline Age4 & -0.122 & $(0.306)$ & -0.149 & $(0.530)$ & 0.143 & $(0.501)$ \\
\hline Age5 & -0.206 & $(0.357)$ & -0.356 & $(0.568)$ & 0.124 & $(0.620)$ \\
\hline Gender & $0.303^{*}$ & $(0.161)$ & \multicolumn{2}{|c|}{-} & \multicolumn{2}{|c|}{-} \\
\hline Edu2 & -0.249 & $(0.745)$ & 0.327 & (1.013) & -2.871 & $(2.134)$ \\
\hline Edu3 & -0.601 & $(1.215)$ & 0.618 & $(1.696)$ & -5.379 & $(3.651)$ \\
\hline Edu4 & -1.121 & $(1.563)$ & 0.550 & $(2.209)$ & -7.464 & (4.725) \\
\hline Marit2 & 0.122 & $(0.162)$ & $0.425^{*}$ & $(0.253)$ & -0.380 & $(0.296)$ \\
\hline Marit3 & 0.365 & $(0.434)$ & -0.147 & $(0.664)$ & $1.794^{*}$ & (1.061) \\
\hline Marit4 & -0.068 & $(0.684)$ & 0.471 & $(1.160)$ & 0.764 & $(1.398)$ \\
\hline Race2 & 0.021 & $(0.153)$ & -0.069 & $(0.203)$ & 0.134 & $(0.250)$ \\
\hline Race3 & $0.406^{* * *}$ & $(0.152)$ & $0.454^{* *}$ & $(0.215)$ & $0.437^{*}$ & $(0.246)$ \\
\hline Race4 & 0.518 & $(0.483)$ & 0.617 & $(0.667)$ & 0.440 & $(0.803)$ \\
\hline Position2 & -0.211 & $(0.161)$ & -0.240 & $(0.209)$ & -0.267 & $(0.268)$ \\
\hline Position3 & $-0.561^{* * *}$ & $(0.158)$ & $-0.505^{* *}$ & $(0.210)$ & $-0.716^{* * *}$ & $(0.256)$ \\
\hline Position4 & -0.282 & $(0.207)$ & -0.145 & $(0.275)$ & -0.458 & $(0.333)$ \\
\hline Position5 & 0.068 & $(0.178)$ & 0.260 & $(0.225)$ & -0.302 & $(0.314)$ \\
\hline Position6 & 0.371 & $(0.891)$ & 0.335 & $(0.918)$ & & \\
\hline Happy & -0.161 & $(0.103)$ & $-0.335^{* *}$ & $(0.136)$ & 0.049 & $(0.173)$ \\
\hline Health & 0.163 & $(0.198)$ & 0.374 & $(0.335)$ & 0.032 & $(0.270)$ \\
\hline Residence2 & 0.124 & $(0.124)$ & 0.213 & $(0.174)$ & 0.093 & $(0.187)$ \\
\hline Residence3 & -0.076 & $(0.116)$ & -0.163 & $(0.155)$ & 0.094 & $(0.188)$ \\
\hline Residence4 & $-0.831^{* * *}$ & $(0.283)$ & $-0.953^{* *}$ & $(0.375)$ & -0.567 & $(0.479)$ \\
\hline Earnings & $-0.833^{* *}$ & $(0.394)$ & -1.313 & $(0.910)$ & -0.722 & $(0.549)$ \\
\hline Income & 1.439 & (1.115) & 0.626 & $(1.468)$ & $6.246^{*}$ & $(3.702)$ \\
\hline Constant & -7.453 & $(12.042)$ & 5.991 & $(17.172)$ & -58.658 & $(38.981)$ \\
\hline$N$ & \multicolumn{2}{|c|}{855} & \multicolumn{2}{|c|}{485} & \multicolumn{2}{|c|}{370} \\
\hline Log likelihood & \multicolumn{2}{|c|}{-480.213} & \multicolumn{2}{|c|}{-270.147} & \multicolumn{2}{|c|}{-198.354} \\
\hline LR chi2 (26) & \multicolumn{2}{|c|}{$90.01^{* * *}$} & \multicolumn{2}{|c|}{$64.41^{* * *}$} & \multicolumn{2}{|c|}{$48.34^{* * *}$} \\
\hline
\end{tabular}

Notes.

(1) Goodness of fit is as follows: the result of Log-likelihood ratio test can reject the hypothesis that all coefficients except for the intercept are 0 at the 0.01 level. Considering the Gender variable, the LR chi2 of male is LR chi2 (25) and female sample is LR chi2 (24), respectively.

(2) Other notes are the same as in Table 2.

and Residence 4 variables for men are statistically significantly negative for no-pay leave. In particular, male workers with higher levels of happiness are less likely to have unpaid leave, keeping a good connection with their employment. In contrast, the estimated coefficient of the Race 3 variable is statistically significantly positive for unpaid leave. This means that male Mainlander workers are more likely to have unpaid leave. Moreover, Table 2 also shows that the estimated coefficients of Edu4, Marit4, and Position3 variables for women are statistically significantly negative for unpaid leave. This indicates that female workers with highest educational attainment, widowed, and of medium level of social class are less likely to have unpaid leave.

Furthermore, Table 3 shows the marginal effect of unpaid leave without economic factors. Although the results are similar to Table 2, some features are still of interest.
For example, the variables of Age3, Age4, and Age5 have smaller marginal effects of unpaid leave than Agel. This means that older workers are in a stronger position to keep their jobs; therefore, they are less likely to take unpaid leave from their employment. In contrast, the variable of Race3 has a larger marginal effect than Racel. This result confirms that Mainlander workers have a higher probability of unpaid leave.

Considering individual earnings and family income, most empirical results are similar to Tables 2 and 3 as shown in Tables 4 and 5. In particular, the estimated coefficient of the Earnings variable is statistically significantly negative for unpaid leave. This means that workers with high earnings are less likely to take unpaid leave from the labour market. However, the estimated coefficients of Income and Marit3 variables for women have a significantly positive effect on 
TABLE 5: Probit marginal effect estimates of unpaid leave with economic factor.

\begin{tabular}{|c|c|c|c|c|c|c|}
\hline \multirow{2}{*}{$\begin{array}{l}\text { Sample } \\
\text { Variables } \\
\end{array}$} & \multicolumn{2}{|c|}{ Overall } & \multicolumn{2}{|c|}{ Male } & \multicolumn{2}{|c|}{ Female } \\
\hline & $d y / d x$ & Std. Err. & $d y / d x$ & Std. Err. & $d y / d x$ & Std. Err. \\
\hline Age2 & 0.107 & $(0.086)$ & 0.131 & $(0.147)$ & 0.145 & $(0.133)$ \\
\hline Age3 & 0.025 & $(0.108)$ & 0.028 & $(0.192)$ & 0.082 & $(0.168)$ \\
\hline Age4 & -0.041 & $(0.104)$ & -0.051 & $(0.182)$ & 0.046 & $(0.161)$ \\
\hline Age5 & -0.070 & $(0.121)$ & -0.122 & $(0.195)$ & 0.040 & (0.199) \\
\hline Gender & $0.103^{*}$ & $(0.054)$ & \multicolumn{2}{|c|}{-} & \multicolumn{2}{|c|}{-} \\
\hline Edu2 & -0.084 & $(0.253)$ & 0.112 & $(0.349)$ & -0.922 & $(0.673)$ \\
\hline Edu3 & -0.204 & $(0.413)$ & 0.212 & $(0.583)$ & -1.728 & (1.148) \\
\hline Edu4 & -0.381 & $(0.531)$ & 0.189 & $(0.760)$ & -2.397 & (1.483) \\
\hline Marit2 & 0.041 & $(0.055)$ & $0.146^{*}$ & $(0.087)$ & -0.122 & $(0.094)$ \\
\hline Marit3 & 0.124 & $(0.147)$ & -0.051 & $(0.228)$ & $0.576^{*}$ & $(0.333)$ \\
\hline Marit4 & -0.023 & $(0.232)$ & 0.162 & $(0.399)$ & 0.245 & $(0.446)$ \\
\hline Race2 & 0.007 & $(0.052)$ & -0.023 & $(0.070)$ & 0.043 & $(0.081)$ \\
\hline Race3 & $0.138^{* * *}$ & $(0.051)$ & $0.156^{* *}$ & $(0.074)$ & $0.140^{*}$ & $(0.079)$ \\
\hline Race4 & 0.176 & $(0.164)$ & 0.212 & $(0.229)$ & 0.141 & $(0.258)$ \\
\hline Position2 & -0.071 & $(0.054)$ & -0.082 & $(0.072)$ & -0.085 & $(0.086)$ \\
\hline Position3 & $-0.191^{* * *}$ & $(0.053)$ & $-0.173^{* *}$ & $(0.072)$ & $-0.230^{* * *}$ & $(0.082)$ \\
\hline Position4 & -0.096 & $(0.070)$ & -0.049 & $(0.094)$ & -0.147 & $(0.107)$ \\
\hline Position5 & 0.023 & $(0.061)$ & 0.089 & $(0.077)$ & -0.097 & $(0.101)$ \\
\hline Position6 & 0.126 & $(0.303)$ & 0.115 & $(0.315)$ & & \\
\hline Happy & -0.055 & $(0.035)$ & $-0.115^{* *}$ & $(0.047)$ & 0.015 & $(0.055)$ \\
\hline Health & 0.055 & $(0.067)$ & 0.128 & $(0.115)$ & 0.010 & $(0.086)$ \\
\hline Residence2 & 0.042 & $(0.042)$ & 0.073 & $(0.060)$ & 0.030 & $(0.060)$ \\
\hline Residence3 & -0.025 & $(0.039)$ & -0.056 & $(0.053)$ & 0.030 & $(0.060)$ \\
\hline Residence4 & $-0.282^{* * *}$ & $(0.096)$ & $-0.328^{* *}$ & $(0.128)$ & -0.182 & $(0.153)$ \\
\hline Earnings & $-0.283^{* *}$ & $(0.134)$ & -0.451 & $(0.313)$ & -0.232 & $(0.177)$ \\
\hline Income & 0.489 & $(0.379)$ & 0.215 & $(0.505)$ & $2.006^{*}$ & $(1.161)$ \\
\hline Predicted probability & \multicolumn{2}{|c|}{0.286} & \multicolumn{2}{|c|}{0.293} & \multicolumn{2}{|c|}{0.255} \\
\hline Observations & \multicolumn{2}{|c|}{855} & \multicolumn{2}{|c|}{485} & \multicolumn{2}{|c|}{370} \\
\hline
\end{tabular}

Notes.

(1) The $d y / d x$ is for discrete change of dummy from 0 to 1.

(2) Other notes are the same as in Table 2.

unpaid leave. This suggests that female workers with high family income and female workers who are divorced or separated have a higher probability of unpaid leave.

\section{Conclusion}

This paper examines the factors influencing unpaid leave in Taiwan. The main empirical results show that older workers, people with highest educational attainment, widows and widowers, worker of medium level of social class, and workers living in east areas are less likely to take unpaid leave in labour market. In particular, male Mainlander workers are more likely to take unpaid leave. Moreover, female workers with highest educational attainment, who have been widowed, and workers of medium level of social class are less likely to have unpaid leave. Considering individual earnings and family income, workers with high earnings are less likely to take unpaid leave. Female workers with high family income and divorced or separated female workers have a higher probability of unpaid leave.

However, because the First Social Image Survey in 2009 has limited information about employers and the laws of parental and family leave, this paper does not discuss the decisions related to unpaid leave which assuredly affect employment behaviour. A possible later analysis could include more factors influencing employers and parental or family leave that deeply affect labour market.

\section{Conflict of Interests}

The authors declare that there is no conflict of interests regarding the publication of this paper.

\section{Acknowledgment}

The authors would like to thank the Center for Survey Research, RCHSS, Academia Sinica for providing the 2009 First Social Image Survey (FSIS) in Taiwan data. 


\section{References}

[1] Y. Chu and L. Su, "The regulations and practices of no-pay leave by enterprises," Taiwan Labor Quarterly, vol. 22, pp. 108-115, 2010 (Chinese).

[2] C. Lin, "Job switch, job tenure, and wage dynamic: an empirical study on College Graduates in Taiwan," in Proceedings of the Annual Conference of ASSA/AEA, Washington, DC, USA, 2003.

[3] H.-L. Chuang, "Job search effectiveness for employed and unemployed college graduate youth in Taiwan," Journal of Asian Economics, vol. 6, no. 2, pp. 247-260, 1995.

[4] Y.-W. Chen, "Once a NEET always a NEET? Experiences of employment and unemployment among youth in a job training programme in Taiwan," International Journal of Social Welfare, vol. 20, no. 1, pp. 33-42, 2011.

[5] W. Hung, "An empirical analysis of health and labour force participation among the young people in Taiwan," International Journal of Social Science and Human Behaviour Study, vol. 1, no. 2, pp. 80-84, 2014.

[6] C. Chiao, "Comments on the review of family care leave system in Taiwan," Taiwan Labor Quarterly, vol. 24, pp. 54-60, 2010 (Chinese).

[7] FSIS, First Social Image Survey, The Centre for Survey Research, Research Centre for Humanities and Social Sciences, Academia Sinica, 2009.

[8] J. Aitchison and S. D. Silvey, "The generalization of probit analysis to the case of multiple responses," Biometrika, vol. 44, no. 1, pp. 131-140, 1957.

[9] S. P. Jenkins, "Lone mothers' employment and full-time work probabilities," The Economic Journal, vol. 102, no. 411, pp. 310320, 1992.

[10] A. Duncan, Cross-Section and Panel Data Econometrics, Lectures and Seminar Programme Notes, University of Nottingham, Nottingham, UK, 2000. 

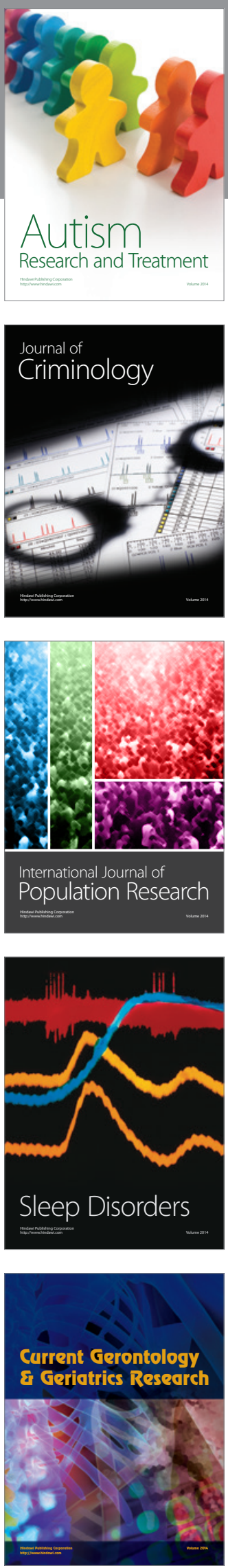
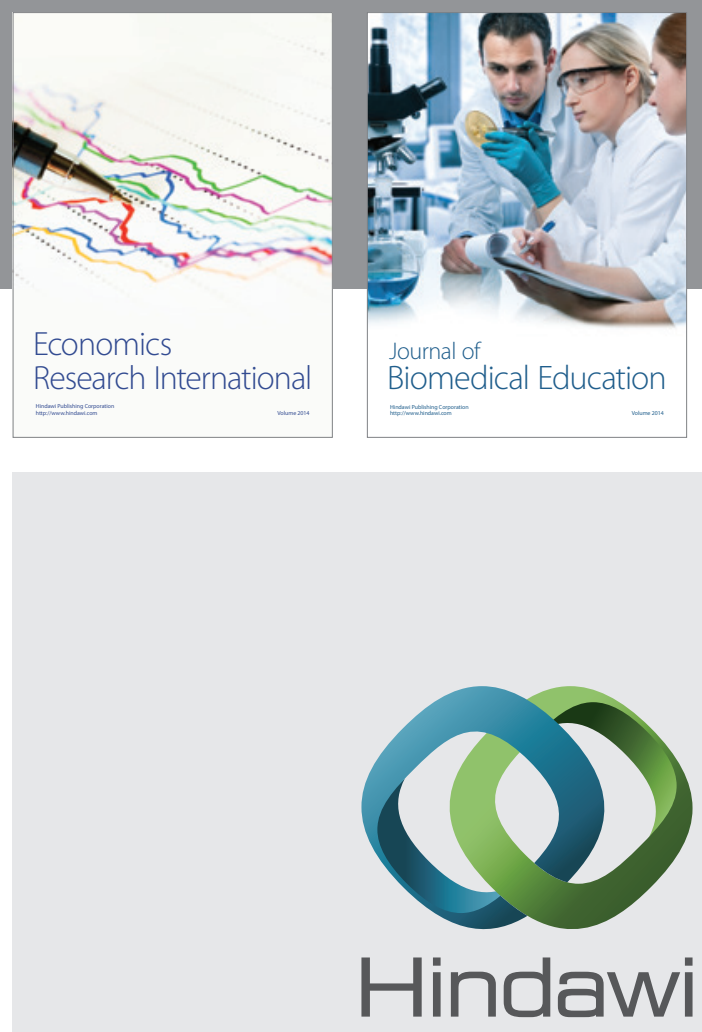

Submit your manuscripts at

http://www.hindawi.com
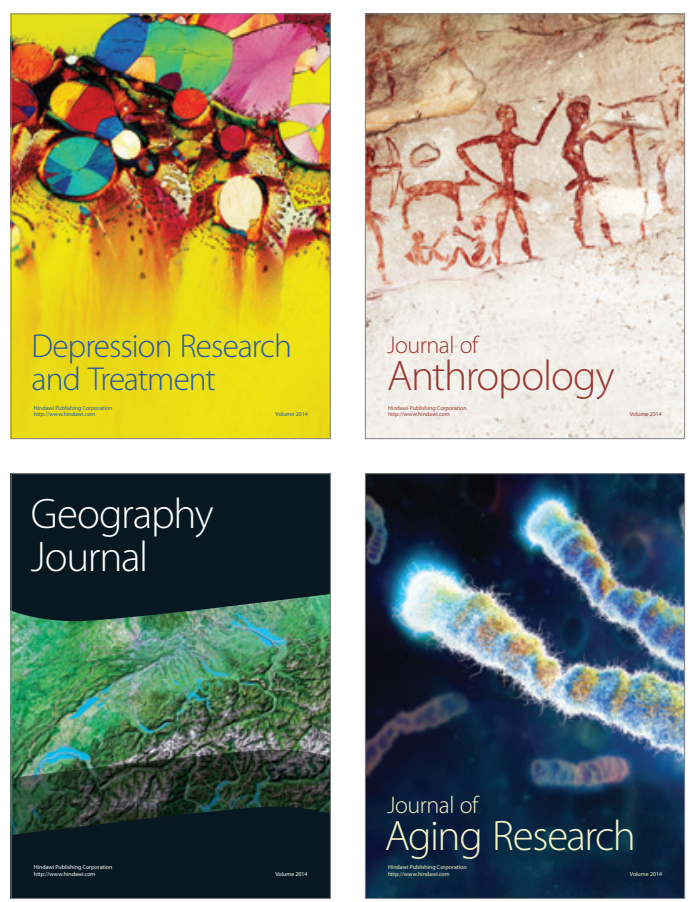
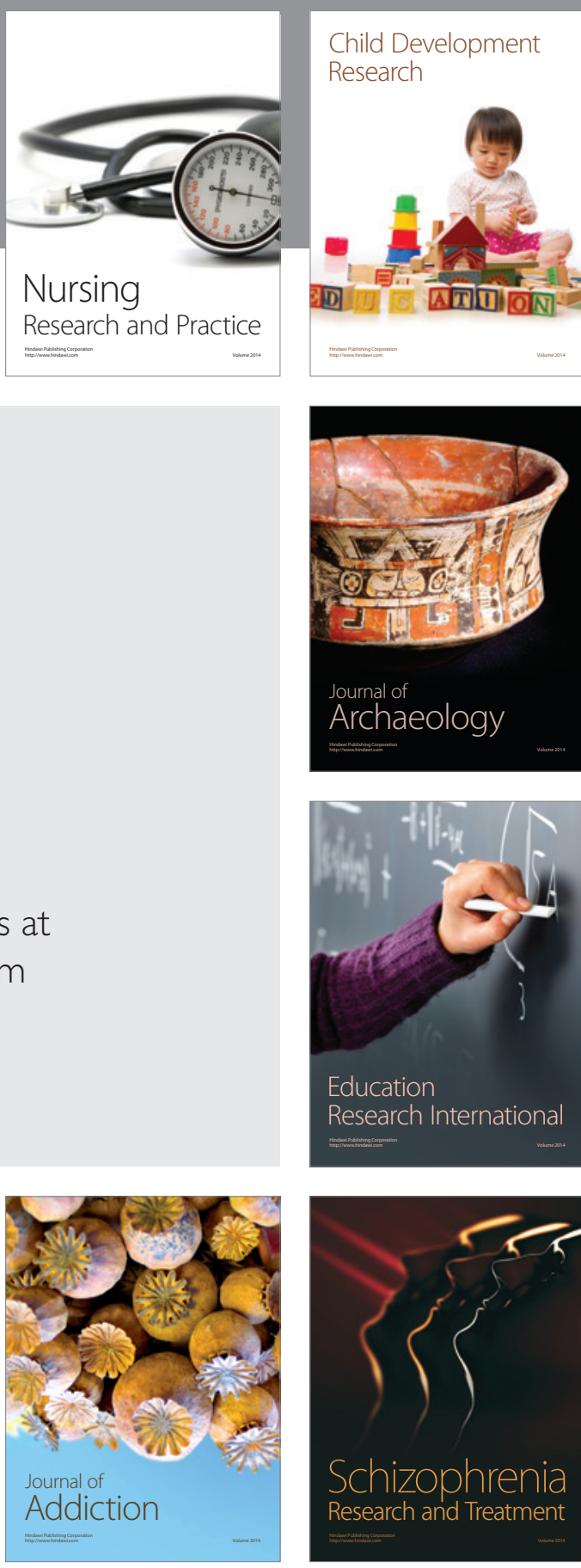

(D)
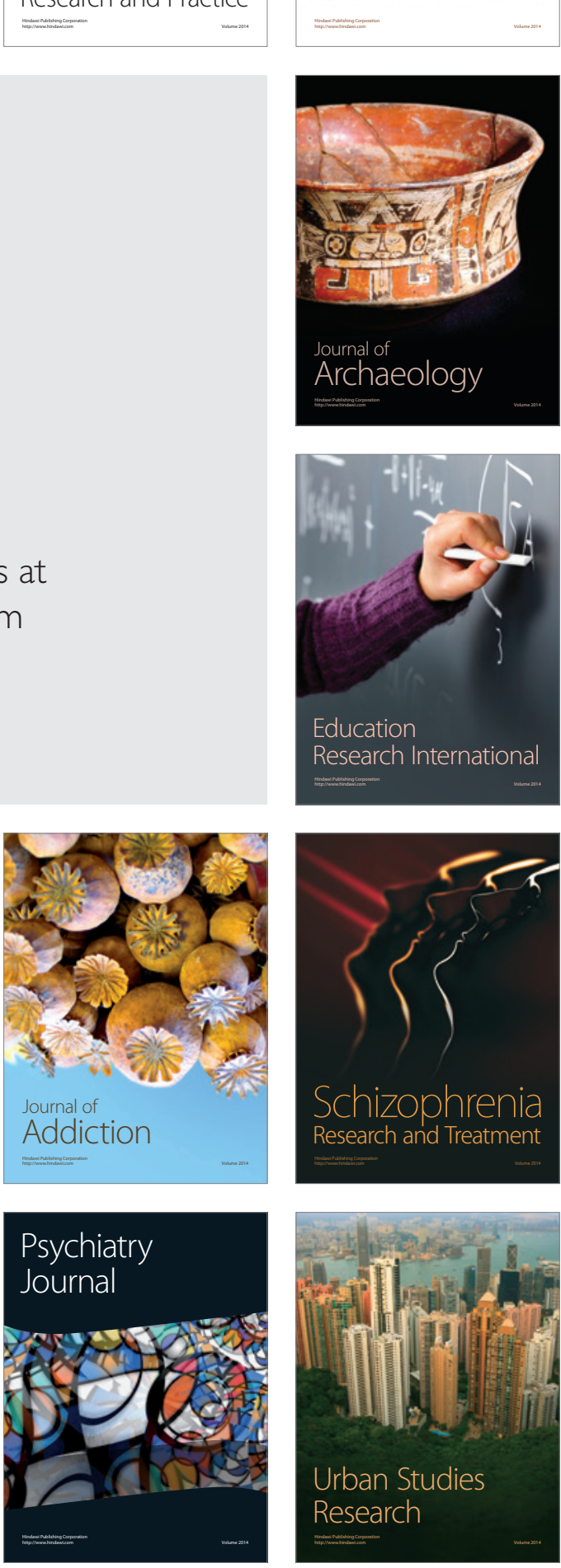